\title{
Change in extreme temperature event frequency over mainland China, 1961-2008
}

\author{
Yaqing Zhou ${ }^{1,2}$, Guoyu Ren ${ }^{2, *}$ \\ ${ }^{1}$ Jinzhong Meteorological Bureau of Shanxi Province, Jinzhong 030600, PR China \\ ${ }^{2}$ Laboratory for Climate Studies, National Climate Center, China Meteorological Administration (CMA), Beijing 100081, PR China
}

\begin{abstract}
Based on homogeneity-adjusted daily temperature data from national stations, the spatial and temporal change in extreme temperature events in mainland China have been analyzed for the period 1961-2008. The analysis shows that the numbers of frost days and ice days were significantly reduced, with the most significant reduction generally in northern China for ice days but more extensively across the country for frost days. Summer days and tropical nights significantly increased along the middle and lower reaches of the Yangtze River and in southern Southwest China. The maximum values of $T_{\max }$ (TXx) and $T_{\min }(\mathrm{TNx})$ and the minimum values of $T_{\max }$ (TXn) and $T_{\min }$ (TNn) generally rose, and TXx and TNx significantly increased in northern China, while TXn and TNn significantly increased across the whole country. A significant reduction at a rate of $-8.23 \mathrm{~d}$ decade $^{-1}\left(-3.26\right.$ d decade $^{-1}$ ) occurred for cool nights (days), and a significant increase at a rate of $8.16 \mathrm{~d} \mathrm{decade}^{-1}$ (5.22 d decade ${ }^{-1}$ ) occurred for warm nights (days). The reduction of cool nights and cool days occurred mainly in winter, but the increase of warm days and warm nights occurred mostly in autumn and summer. Extreme cold indices were reduced, mainly after the mid-1980s, while extreme warm indices increased remarkably after the mid-1990s. The analysis also shows that, for North China, the urbanization effect on the series of extreme temperature indices was statistically significant for the negative trends of frost days, diurnal temperature range, cool nights and cool days, and for the positive trends of summer days, tropical nights, TNx, TNn, and warm nights.
\end{abstract}

KEY WORDS: Extreme temperature index - Maximum temperature - Minimum temperature · Climate change $\cdot$ Urbanization effect $\cdot$ Mainland China

\section{INTRODUCTION}

Extreme climate has recently received more attention due to its huge impacts on economic and social development. In the past decade, many analyses have been conducted on long-term change in extreme climate events, and a number of scientific conclusions have been reached (e.g. Easterling et al. 2000, IPCC 2007, Ding et al. 2006). Based on 27 extreme temperature and precipitation indices defined by the Expert Team of Climate Change Detection, Monitoring and Index (ETCCDMI), the global variations in extreme climate have been analyzed by Alexander et al. (2006). Results showed widespread significant changes in temperature extremes associated with warming from 1951 to 2003. More than $70 \%$ of the Earth's land area underwent a significant reduction in the number of cool nights and a significant increase in the number of warm nights. Positive trends occurred in daily minimum and maximum temperatures over the entire globe, while the minimum temperature change was greater. In the analysis of daily temperature and precipitation indices in Europe from 1946 to 1999, conducted by Klein Tank \& Konnen (2003), cool days (nights) were shown to be significantly reduced, while warm days (nights) were significantly increased. Similar conclusions have also been drawn from studies of, e.g. SE Asia, the South Pacific, South America, and the Asian Pacific region (Manton et al. 
2001, Brabson \& Palutikof 2002, Vincent et al. 2005, Choi et al. 2009).

Chinese studies (Tang et al. 2005, Ding et al. 2006) show that, in recent decades, increasing trends in mean maximum temperatures have occurred in northern China, while weak decreasing or insignificant trends have occurred in southern China. Mean minimum temperatures have increased all over China. Due to the asymmetry of the maximum and minimum temperature variations, the diurnal temperature range (DTR) showed a downward trend (Zhou \& Ren 2009). Nation-wide cold waves gradually weakened, frost days were significantly reduced, warm days (nights) increased, cool days (nights) decreased, and cool nights showed a more significant decreasing trend (Zhai \& Pan 2003, Ren et al. 2005, 2010a, Liu et al. 2006, Hu et al. 2007). The annual average number of extreme high temperature events has increased, while the extreme low temperature events have decreased (Zhang \& Qian 2008). Extreme cold indices varied prominently in winter, and trends in the temperature indices have strong regional characteristics and seasonal variations in China (Yan et al. 2002, Qian \& Lin 2004, Ding et al. 2009, Yang et al. 2010). According to research results for North China, East China, and some other regions (Gong \& Han 2004, Ye et al. 2008, You et al. 2008, Cui et al. 2009, Shi et al. 2009), the variation trends in cold indices and the warm indices based on percentile thresholds for different regions were generally similar, with certain differences in magnitude. However, the variation trends for extreme high temperature indices were spatially quite different.

Differences among the studies of long-term variations in extreme climate events in China resulted primarily from the different periods and areas analyzed and from the different index criteria used. The adoption of common definitions for such indices could prove to be beneficial for the comparison of research results. Further attention should also be given to the procedure used in dealing with daily temperature data. The use of inhomogeneous data in previous studies (e.g. Tang et al. 2005, You et al. 2008, Zhou \& Ren 2009) on changes in extreme temperature events in China might have contributed to the inconsistencies in their research results.

Applying the homogeneity-adjusted daily maximum and minimum temperature data from 1961 to 2008 and the internationally comparable extreme temperature indices recommended by the ETCCDMI (Zhang \& Yang 2004; and also at http://cccma.seos. uvic.ca/etccdmi/index.shtml), we have updated analyses of the spatial and temporal variations over the past $48 \mathrm{yr}$ in the extreme temperature indices for mainland China, with a focus on the trends in the series of indices. In order to understand the possible biases induced by local human activities in the country, an urbanization effect on the trends of the extreme temperature indices was preliminarily evaluated for North China.

\section{DATA AND METHODS}

\subsection{Data and quality control}

Daily temperature records were chosen from the China Homogenized Historical Temperature Datasets (CHHTD) compiled by the National Meteorological Information Center of the China Meteorological Administration (CMA), including the daily maximum and minimum temperature data from 1951 to 2008, which was recorded at national-level ground weather stations, or national basic meteorological stations and reference climatic stations (hereinafter referred to as national stations). The data sets were quality controlled and homogeneity adjusted. The homogeneity adjustment method was described by Liu \& Li (2003) and Li et al. (2004). In short, it involved selecting time series from 5 stations that were highly positively correlated with the candidate stations, and combining the 5 temperature series into a reference series. Subsequently, they checked whether significant discontinuous points existed in different candidate series by comparison with the reference series. The reasonableness of the discontinuous points was determined according to station metadata. Once all the significant discontinuities were detected and proved, the correction value could be obtained from the offsets derived from the difference series (based on differences between candidate and reference data).

By investigating metadata of weather stations, it was found that 328 of 526 stations had relocation records; 155 stations had been moved once and 173 stations had been moved more than once. Homogeneity detection showed that significant discontinuous points existed in the maximum temperatures of 177 stations and in the minimum temperatures of 213 stations. Correction was carried out for the discontinuous points, and the corrected stations then accounted for 34 and $40 \%$ of the total, respectively (Li et al. 2004).

The large-scale establishment of stations in China was started in the mid- to late 1950s, accompanied by standardized and improved meteorological records, and thus the data period 1961-2008 was selected for the present study. According to the criteria that the 


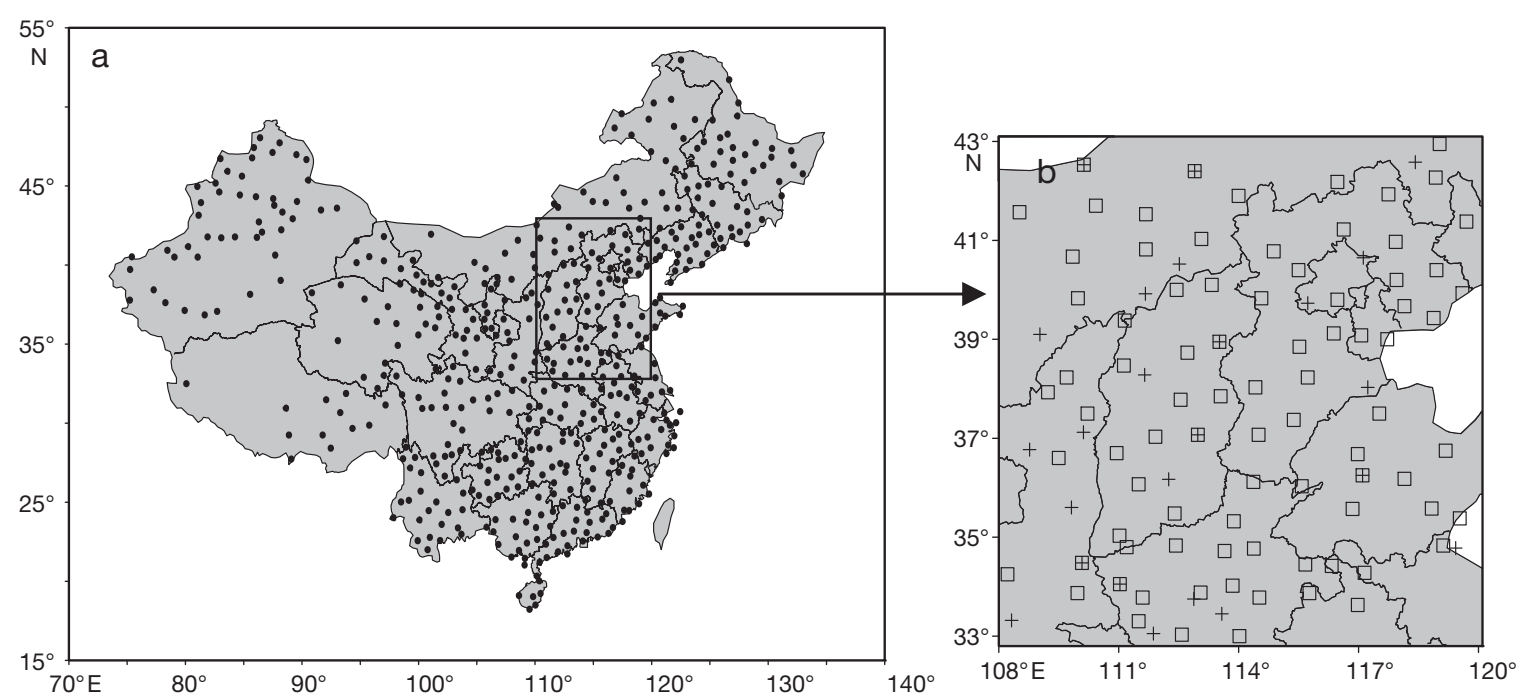

Fig. 1. Distribution of the weather stations used in the present study: (a) the 526 stations in mainland China and (b) stations in North China, with squares indicating the national stations and crosses indicating the rural stations

series length is no less than $48 \mathrm{yr}$ and no more than $2 \%$ of the data are missing, the data of 526 stations were finally selected for analysis (Fig. 1).

Quality control was repeated for the homogenized daily temperature data with Rclimdex software (Zhang \& Yang 2004). Quality control was performed in 2 steps: (1) if the maximum temperature minus minimum temperature was negative, the record was marked as unreasonable and dealt with as a missing value, and (2) records with standard deviations 4 -fold greater than the average were marked as outliers. Artificial determination was carried out according to the corresponding records of neighboring stations, and reasonable records were retained, while unreasonable ones were dealt with as missing values. After the check, outliers were detected in 358 stations, of which 10 daily temperature values of 6 stations were determined as unreasonable, accounting for 5 per million of the total records.

\subsection{Definition of extreme temperature indices}

If the weather status shows a large deviation from the mean state it can be termed an extreme event in a statistical sense. We used 15 extreme temperature indices (see Table 1), of which 13 are based on definitions by the ETCCDMI and 2 additional indices involved monthly average maximum and minimum temperatures. With the period 1971-2000 taken as a reference period, Rclimdex software was used to calculate the time series and linear trends of the extreme temperature indices for each station, and the statistical significance of the trends were evaluated.
The extreme temperature indices were divided into 3 types. The first type was based on original observation data and fixed thresholds, and was considered 'absolute'. The 4 absolute indices include frost days, summer days, ice days, as well as tropical nights. Due to the vast area and complex climate in China, the following considerations were also taken into account. For the 4 absolute indices, if no record of an extreme event occurred at a certain station within a period of two-thirds of the $48 \mathrm{yr}$, the estimated linear trend was considered unreliable, and thus the station was not included in the statistics of index time series. The second index type utilized the means and extremes of daily maximum and minimum temperatures, termed extreme value indices, including mean maximum (minimum) temperature, maximum $T_{\max }(\mathrm{TXx})$ and $T_{\min }(\mathrm{TNx})$, minimum $T_{\max }(\mathrm{TXn})$ and $T_{\min }(\mathrm{TNn})$, and DTR. The third type of indices was based on relative or floating thresholds, termed the relative indices, including cool days (nights) and warm days (nights). In the calculation of these indices, the 90th (10th) percentile of the daily maximum (minimum) temperature data at a certain station in the period 1971-2000 was taken as the upper (lower) threshold. If a daily maximum temperature was greater (less) than the upper (lower) threshold, then it was considered a warm (cool) day event. Similarly, if a daily minimum temperature was greater (less) than the upper (lower) threshold, then it was considered a warm (cool) night event. The specific definitions of the indices are listed in Table 1. In order to facilitate comparisons with other research results, the percentages of days were converted to the days with daily maximum (minimum) temperatures greater (less) than the upper (lower) thresholds. 
Table 1. Extreme temperature indices used in the present study (modified according to Zhang \& Yang 2004) and their linear trends in mainland China, 1961-2008. All trends in the table are statistically significant at the 0.05 confidence level. Data given as d decade ${ }^{-1}$ for absolute and relative indices, and ${ }^{\circ} \mathrm{C}$ decade ${ }^{-1}$ for extreme value indices. TN: daily minimum temperature; TX: daily maximum temperature

\begin{tabular}{|c|c|c|c|}
\hline $\begin{array}{l}\text { Index } \\
\text { abbrevia }\end{array}$ & Term & Definition & $\begin{array}{l}\text { Linear } \\
\text { trend }\end{array}$ \\
\hline \multicolumn{4}{|c|}{ Absolute indices } \\
\hline FD0 & Frost days & Annual count when $\mathrm{TN}<0^{\circ} \mathrm{C}$ & -3.48 \\
\hline SU25 & Summer days & Annual count when $\mathrm{TX}>25^{\circ} \mathrm{C}$ & 2.69 \\
\hline ID0 & Ice days & Annual count when $\mathrm{TX}<0^{\circ} \mathrm{C}$ & -2.32 \\
\hline TR20 & Tropical nights & Annual count when $\mathrm{TN}>20^{\circ} \mathrm{C}$ & 2.47 \\
\hline \multicolumn{4}{|c|}{ Extreme value indices } \\
\hline TXa & Average TX & Monthly mean value of TX & 0.26 \\
\hline $\mathrm{TNa}$ & Average TN & Monthly mean value of TN & 0.40 \\
\hline DTR & $\begin{array}{l}\text { Diurnal tempera- } \\
\text { ture range }\end{array}$ & $\begin{array}{l}\text { Monthly mean value of difference } \\
\text { between TX and TN }\end{array}$ & -0.15 \\
\hline $\mathrm{TXx}$ & Maximum TX & Monthly maximum value of TX & 0.15 \\
\hline $\mathrm{TNx}$ & Maximum TN & Monthly minimum value of TX & 0.25 \\
\hline TXn & Minimum TX & Monthly maximum value of TN & 0.35 \\
\hline TNn & Minimum TN & Monthly minimum value of TN & 0.58 \\
\hline \multicolumn{4}{|c|}{ Relative indices } \\
\hline TN10p & Cool nights & $\begin{array}{l}\text { Percentage of days when } \\
\text { TN }<10 \text { th percentile }\end{array}$ & -8.23 \\
\hline TX10p & Cool days & $\begin{array}{l}\text { Percentage of days when } \\
\text { TX }<10 \text { th percentile }\end{array}$ & -3.26 \\
\hline TN90p & Warm nights & $\begin{array}{l}\text { Percentage of days when } \\
\text { TN > 90th percentile }\end{array}$ & 8.16 \\
\hline TX90p & Warm days & $\begin{array}{l}\text { Percentage of days when } \\
\text { TX > 90th percentile }\end{array}$ & 5.22 \\
\hline
\end{tabular}

\subsection{Statistical analysis}

The least squares method was used for calculation of the linear trend, and the Kendall-tau non-parametric test method was adopted for testing the statistical significance of the linear trend (Kendall \& Gibbons 1981). The average time series for China was obtained according to the grid area weighted average method (Jones \& Hulme 1996), with a grid size of $2.5^{\circ} \times 2.5^{\circ}$. Seasons were divided into spring (MarchMay), summer (June-August), autumn (SeptemberNovember) and winter (December-February of the following year), and annual mean (total) values were those from January to December.

\subsection{Urbanization effect analysis}

In order to quantitatively evaluate the urbanization effect on the linear trend of the extreme temperature indices, we used a subset of data from 142 surface temperature reference stations (rural stations) in China (Ren et al. 2010b, Zhang et al. 2010) to analyze the difference in index trends between national and rural stations, with North China as a case study. The 142 rural stations were selected from 2400 stations, including all of the national stations and 1700 ordinary stations. A number of indicators were considered, such as the settlement population near a station, the distance of the observational grounds from city centers, and the ratio of built-up area to total area within a radius of $2 \mathrm{~km}$ from the observational grounds (Ren et al. 2010b, Ren \& Ren 2011). North China was defined as the area between $33-43^{\circ} \mathrm{N}$ and $108-120^{\circ} \mathrm{E}$, where 84 national stations and 24 rural stations are located.

The following terms were defined with reference to Ren et al. (2008), Zhou \& Ren (2009) and Zhang et al. (2011). The urbanization effect refers to the linear trends in extreme temperature indices recorded at urban or national stations and caused by the strengthening of the urban heat island (UHI) effect and other local anthropogenic factors, expressed as $\Delta X_{\mathrm{ur}} . X_{\mathrm{u}}$ is the linear trend of an extreme temperature index at an urban or national station, and $X_{\mathrm{r}}$ is the linear trend of an extreme temperature index at a rural station. The urbanization effect $\left(\Delta X_{\mathrm{ur}}\right)$ is expressed as:

$$
\Delta X_{\mathrm{ur}}=X_{\mathrm{u}}-X_{\mathrm{r}}
$$

If $\Delta X_{\mathrm{ur}}>0$, the extreme temperature index series rises relatively or increases due to the urbanization effect; if $\Delta X_{\mathrm{ur}}=0$, no urbanization effect exists; and if $\Delta X_{\mathrm{ur}}<$ 0 , the extreme temperature index series declines relatively or is reduced due to the urbanization effect.

Contribution of the urbanization effect refers to the proportion of the urbanization effect to the overall trend of an extreme temperature index series at an urban or national station, expressed as $E_{\mathrm{u}}(\mathrm{in} \%)$ :

$$
E_{\mathrm{u}}=\left|\Delta X_{\mathrm{ur}} / X_{\mathrm{u}}\right| \times 100=\left|\left(X_{\mathrm{u}}-X_{\mathrm{r}}\right) / X_{\mathrm{u}}\right| \times 100
$$

If $E_{\mathrm{u}}=0$, the urbanization effect shows no contribution to the overall trend of the extreme temperature index series at the urban or national station; if $E_{\mathrm{u}}=$ $100 \%$, the linear trend of the extreme temperature index series at the urban or national station is entirely caused by the urbanization effect. In practical calculations, $E_{\mathrm{u}}$ may exceed $100 \%$ in a few cases, indicating that unknown local factors might have had an effect; we adjusted the $E_{\mathrm{u}}$ of such cases to $100 \%$. 


\section{TRENDS OF EXTREME TEMPERATURE INDICES}

\subsection{Absolute indices}

The extreme index with a fixed threshold is called the absolute index. Table 1 shows the linear trends in extreme temperature indices for mainland China, and Fig. 2 shows the anomaly time series curves of absolute indices. Frost days underwent a slight decrease prior to the mid-1980s, and a rapid decline after 1987, leading to a reduction of almost $17 \mathrm{~d}$ in the last 48 yr. Similarly, ice days also showed a decreasing trend with significant reduction occurring after the mid-1980s. However, the variations in ice days were more moderate than those in frost days. Summer days showed negative anomalies, mostly prior to the mid-1990s, but a turning point occurred in 1994, and positive anomalies prevailed after 1997, with the maximum being reached in 2006 and 2007. Similar to summer days, the variations in tropical nights have also accelerated considerably since 1994, reaching a maximum in 2005.

Frost days were significantly reduced across the country (Fig. 3a). This is consistent with the conclusions reached by Zhai \& Pan (2003) as well as Qian \& Lin (2004). Ice days occurred in the areas north of $32^{\circ} \mathrm{N}$, mainly with a deceasing trend. The areas with significant reduction were primarily concentrated in northern China, with scope and degree smaller than those of frost days (Fig. 3b). Summer days at most stations in China showed an increasing trend (Fig. 3c), and the significant increasing trends, $>5 \mathrm{~d} \mathrm{decade}^{-1}$, generally occurred in the northeastern part of the Inner Mongolia Autonomous Region, in the middle and lower reaches of the Yangtze River, and in most of Yunnan Province. Tropical nights also mostly showed an increasing trend, but the areas with significant increase were mainly concentrated in eastern China, in the southern part of Southwest China, and in the coastal zone of South China (Fig. 3d).

In summary, absolute cold indices for mainland China showed a decreasing trend and, in general, have been declining significantly since the mid1980s. However, warm indices mainly showed an increasing trend, but significant variation occurred till the mid-1990s. As viewed from a spatial distribution of trends, cold indices showed a more significant decreasing trend in northern China, while primarily in the middle and lower reaches of the Yangtze River and in the southern part of Southwest China the warm index significantly increased.

\subsection{Extreme value indices}

The temporal variations in annual mean maximum and minimum temperatures, as well as in DTR, in the past $48 \mathrm{yr}$ are shown in Fig. 4. Both mean maximum and minimum temperatures showed increasing trends.
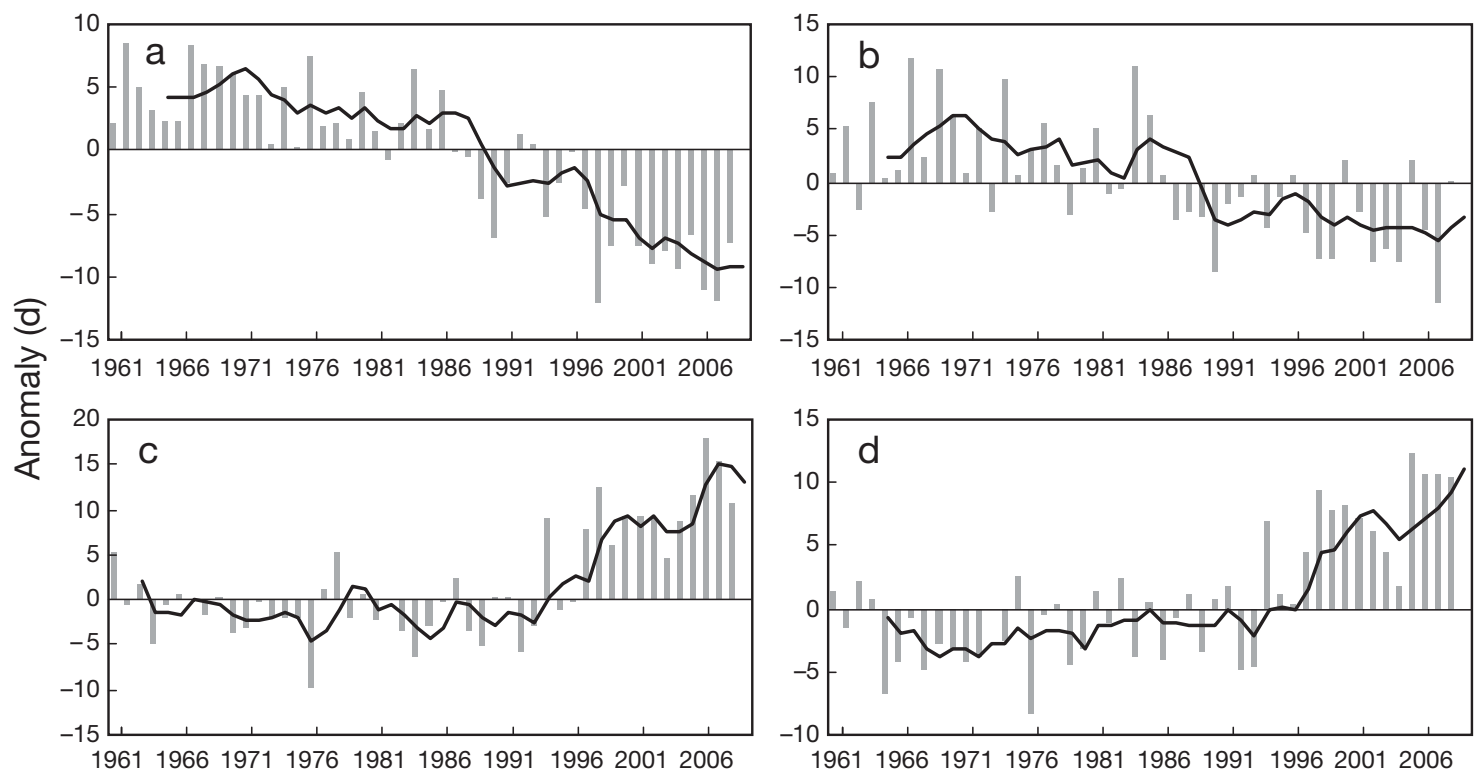

Fig. 2. Anomalies of the country-averaged annual (a) frost days (FD0), (b) ice days (ID0), (c) summer days (SU25), and (d) tropical nights (TR20) in mainland China, 1961-2008. The anomalies are relative to 1971-2000 mean values. The curves are 5 yr running means 

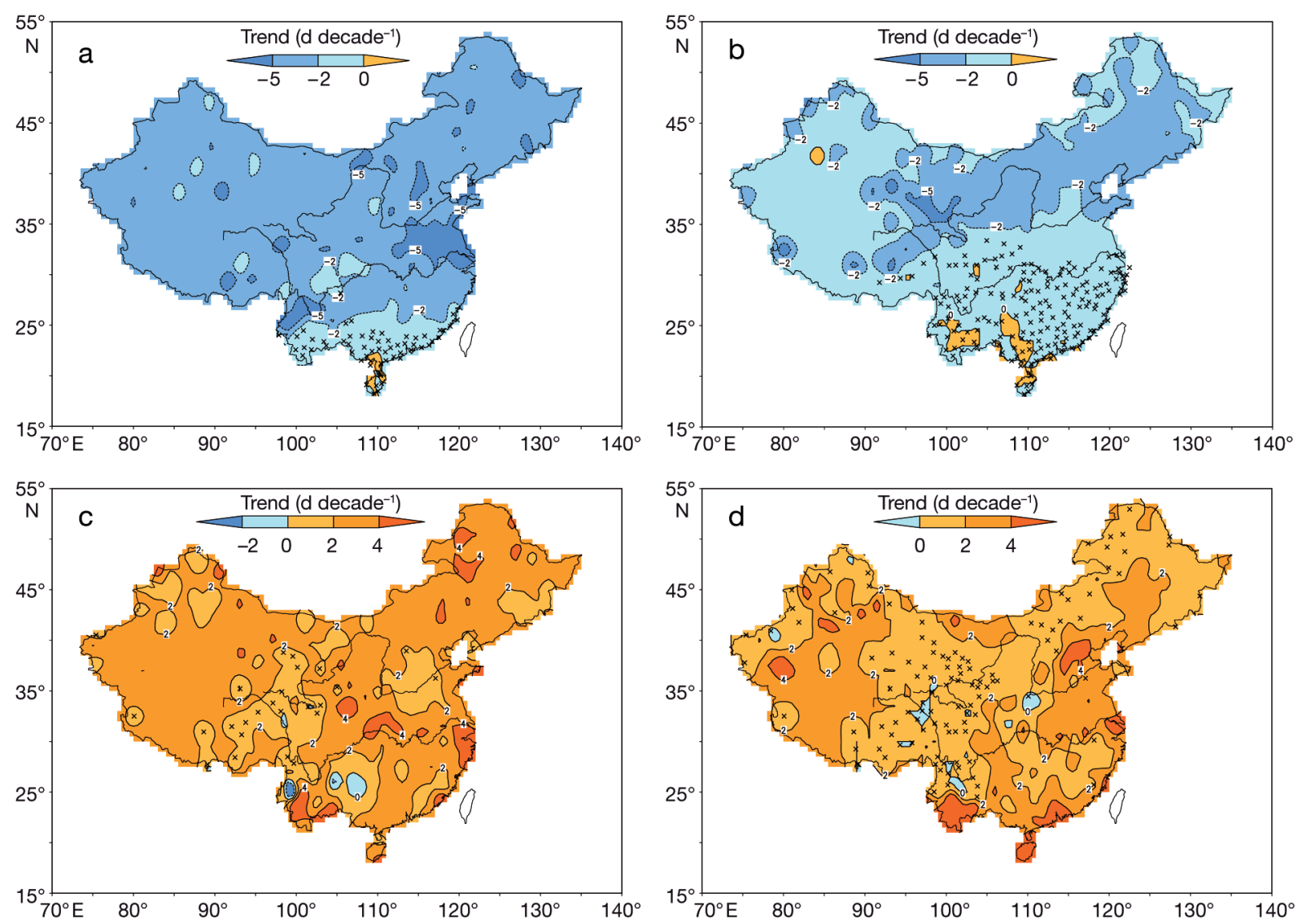

Fig. 3. Trends in the numbers of (a) frost days (FD0), (b) ice days (ID0), (c) summer days (SU25), and (d) tropical nights (TR20) in mainland China, 1961-2008. Crosses denote that linear trends were unavailable due to the sparseness of the extreme temperature events. Data given as d decade ${ }^{-1}$

The maximum temperatures fluctuated prior to the 1990 s, and then began to rise significantly. However, the minimum temperature has steadily risen since the late 1970s, and the upward trend became more prominent in the late 1980s. Because of the asymmetry of maximum and minimum temperature variations, DTR underwent a significant decrease. However, the decreasing trend in DTR mainly occurred prior to the mid-1980s, and became insignificant after that time. DTR was linearly reduced by $0.72{ }^{\circ} \mathrm{C}$ in the country on the whole during the last $48 \mathrm{yr}$.

Extreme values of daily maximum and minimum temperatures showed increasing trends, and $\mathrm{TNn}$ rose more significantly. The increasing trend in $\mathrm{TNn}$ was as great as $0.58^{\circ} \mathrm{C}$ decade $^{-1}$, while that of TXx was only $0.15^{\circ} \mathrm{C}$ decade $^{-1}$. It is also evident in Fig. 5 that TNn showed an overall increasing trend, with the trend more obvious in the late 1980s and 1990s. Since the beginning of the 21st century, however, TNn has generally been stable or even declining, with the exception of 2007. TXn varied insignificantly before the mid-1980s and then rose slowly. Its variation has been similar to that of TNn since the mid- to late 1980s. However, TNx and TXx showed relatively stable variations prior to the mid-1990s, and after that they rose rapidly and have remained at a high level since 2000 .

As Fig. 6a shows, TXx increased in most areas, with the general trend $<0.5^{\circ} \mathrm{C}$ decade $^{-1}$, while the areas with declining trends were mainly in the southeastern part of North China and the middle and upper reaches of the Yangtze River. Compared with TXx, the extent with a downward trend shrunk for TNx (Fig. 6b), while the extent with an upward trend expanded. The areas with increasing trends $>0.5^{\circ} \mathrm{C}$ decade $^{-1}$ were mainly located in northern China. Compared with TXX and TNx, the extents with rising trends of TXn and TNn were generally broader. TXn (Fig. 6c) increased in most areas, especially in Northeast China and in the northern part of Xinjiang province, with the rising trend $>0.5^{\circ} \mathrm{C}_{\text {decade }}{ }^{-1}$. TNn (Fig. 6d) rose considerably throughout country, and the increasing trend was $>0.5^{\circ} \mathrm{C}_{\text {decade }}{ }^{-1}$ in most regions, with some stations in Northeast China, 

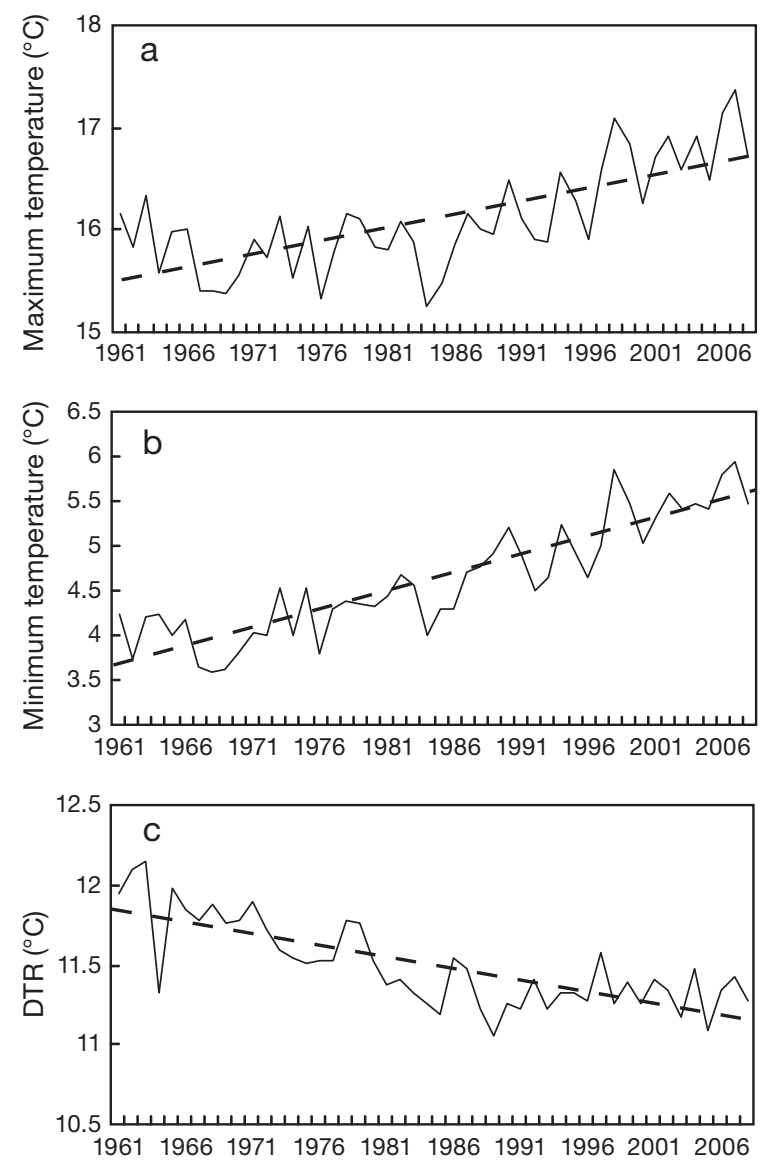

Fig. 4. Country-averaged annual mean (a) maximum temperature, (b) minimum temperature, and (c) diurnal temperature range (DTR) in mainland China, 1961-2008. The dashed lines are linear trends

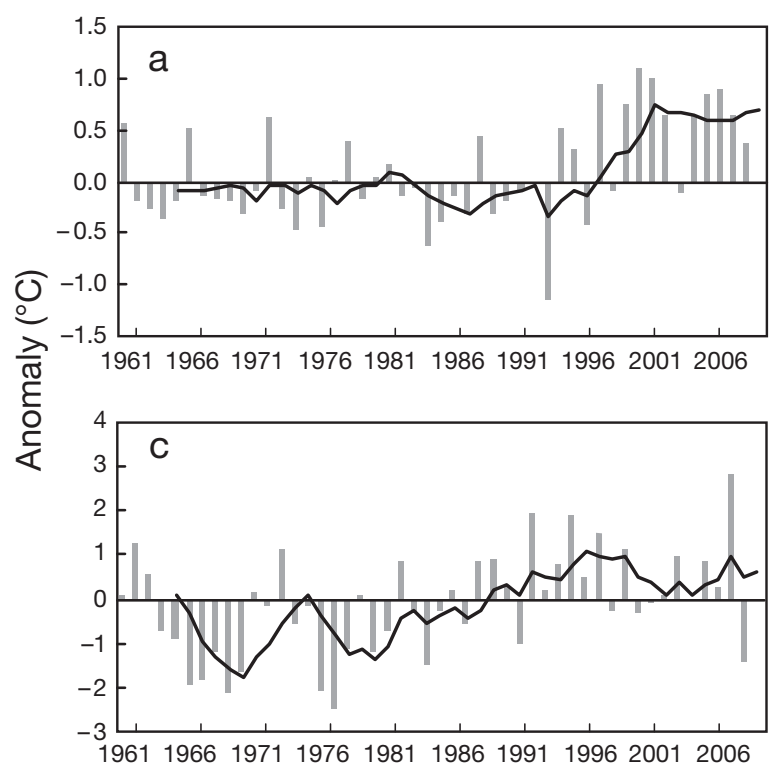

North China, and the northern part of Xinjiang province reaching $1.0^{\circ} \mathrm{C}$ decade $^{-1}$ or even more.

In summary, the mean and maximum and minimum values of daily maximum and minimum temperatures showed overall increasing trends, while DTR was significantly decreased. The mean maximum temperature has risen significantly since the 1990s, while the mean minimum temperature began to rise steadily in the late $1970 \mathrm{~s}$, and the trend became more prominent in the late 1980s. Because of the asymmetry of maximum and minimum temperature variations, DTR experienced a significant decline, especially prior to the mid-1980s.

TXn and TNn have increased significantly since the mid-1980s, while TXx and TNx have increased rapidly since the mid-1990s. A noteworthy phenomenon was that TNn and TXn have generally showed a stable or even declining trend since 2000, while TNx and TXx have remained at a high level since that time. Significant upward trends in TXx and TNx occurred in northern China, while TXx underwent an obvious downward trend in southern North China and the middle and lower reaches of the Yangtze River. TXn and TNn increased significantly across the whole country, but TNn increased more strongly.

\subsection{Relative indices}

Table 1 shows that cool nights (days) significantly decreased with a trend of $-8.23 \mathrm{~d}^{\text {decade }}{ }^{-1}(-3.26 \mathrm{~d}$
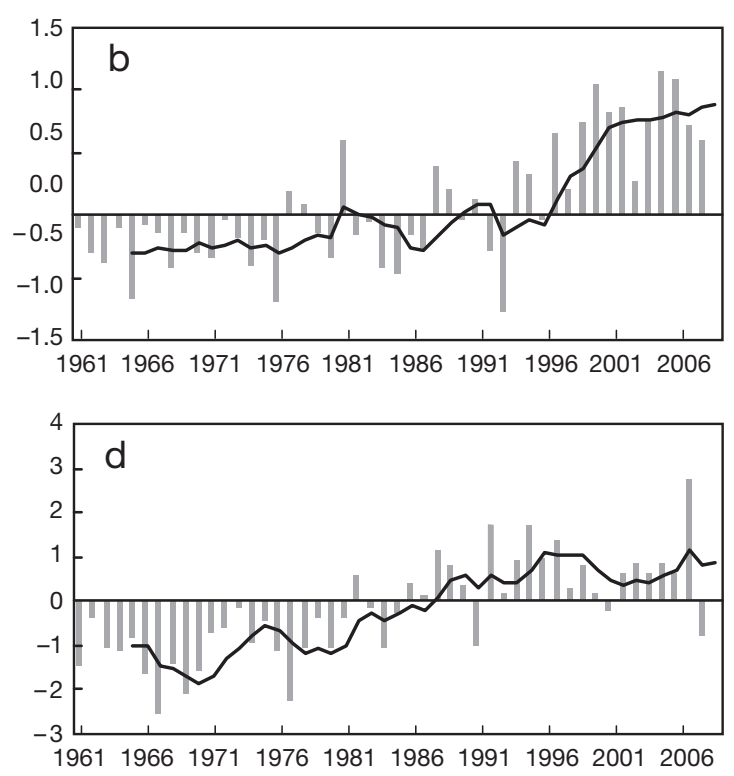

Fig. 5. Anomalies of the country-averaged annual (a) maximum $T_{\max }(\mathrm{TXx})$, (b) maximum $T_{\min }(\mathrm{TNx}),(\mathrm{c}) \operatorname{minimum} T_{\max }(\mathrm{TXn})$, and (d) minimum $T_{\min }$ (TNn) in mainland China, 1961-2008. The anomalies are relative to 1971-2000 mean values. The curves are 5 yr running means 

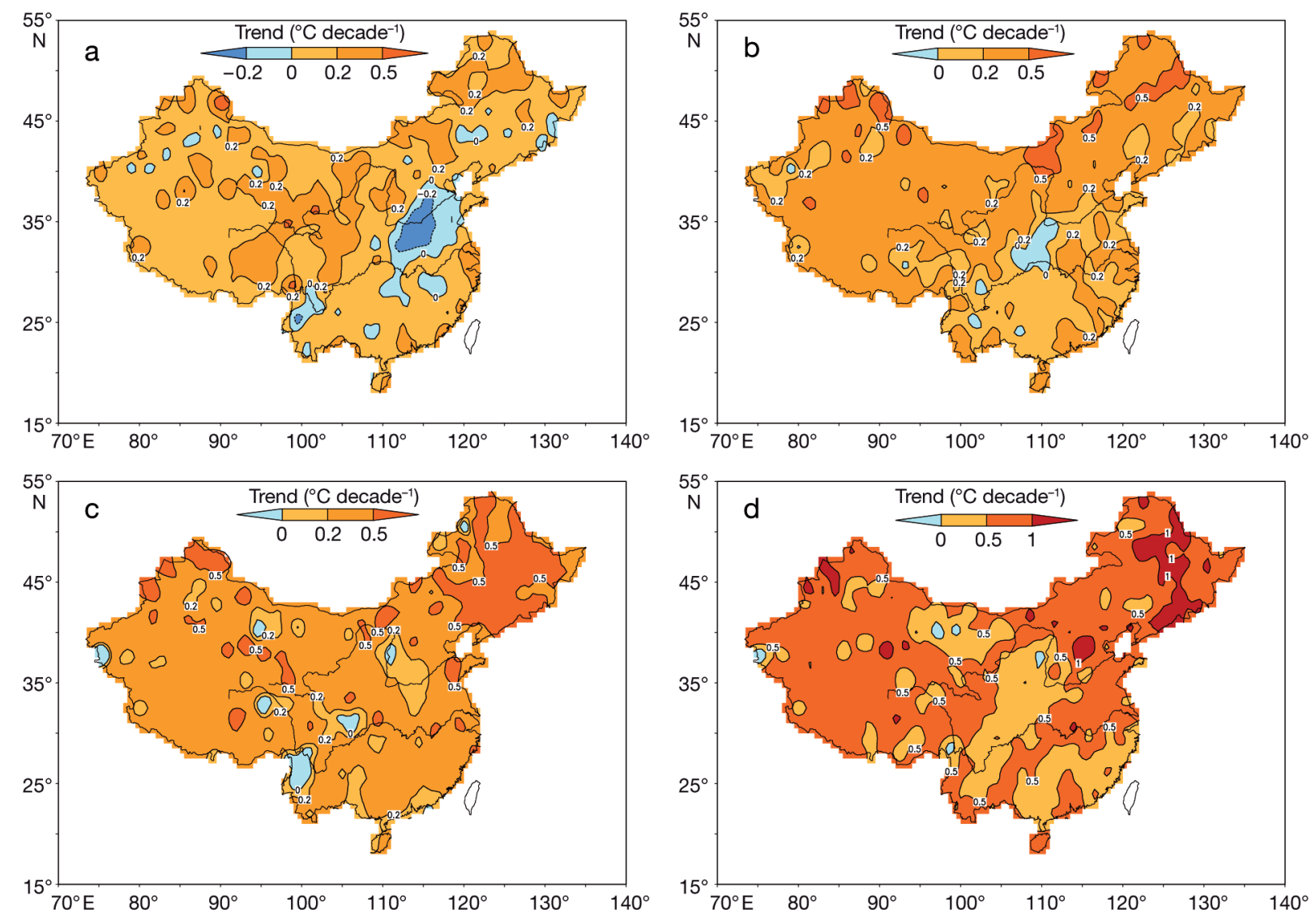

Fig. 6. Trends in distributions of (a) maximum $T_{\max }(\mathrm{TXx})$, (b) maximum $T_{\min }(\mathrm{TNx})$, (c) minimum $T_{\max }(\mathrm{TXn})$, and (d) minimum $T_{\min }(\mathrm{TNn})$ in mainland China, 1961-2008. Data given as ${ }^{\circ} \mathrm{C}$ decade $^{-1}$

decade $^{-1}$ ) during the period 1961-2008, while warm nights (days) significantly increased with a trend of $8.16 \mathrm{~d}_{\text {decade }}{ }^{-1}$ (5.22 d decade ${ }^{-1}$ ). Cool days (nights) primarily showed positive anomalies before the late 1980s, followed by a rapid decline, and negative anomalies have been observed for 19 out of $21 \mathrm{yr}$ since 1987 (Fig. 7a,b). Warm days (nights) showed negative anomalies for most years before 1987, followed by positive and negative anomalies, which alternated till the early 1990s and substantially increased after 1994, with a negative anomaly occurring in only $1 \mathrm{yr}$ during the last $15 \mathrm{yr}($ Fig. $7 \mathrm{C}, \mathrm{d})$. More significant changes occurred for cool (warm) nights than for cool (warm) days. These results are generally consistent with what Choi et al. (2009) found for the Asian Pacific region, but the changing trends obtained here are larger, except for cool days, for which both had similar trends. The trends reported here are also a little bit larger than those given by previous Chinese researchers. The difference might have been due to the different datasets, data processing methods, and lengths of the time periods used in the studies.
Spatial characteristics of trends of the relative extreme temperature indices are displayed in Fig. 8. Cool days significantly declined in northern China, and the areas with increasing trends were mainly in Southwest China (Fig. 8a). For cool nights, with a few exceptions in the eastern part of Southwest China, more significant decrease was observed in the country, with most areas registering downward trends of $>5 \mathrm{~d} \mathrm{decade}^{-1}$. Northeast China, the northern part of North China, the eastern part of Northwest China, and the southern part of Southwest China witnessed an even larger decrease of $>10 \mathrm{~d} \mathrm{decade}^{-1}$ (Fig. 8b). Warm days were reduced in a few stations in the central region and the eastern part of Southwest China, and they significantly increased in other regions, notably in northern China, in the southern part of Southwest China, and in coastal areas of South China, with the increasing trend mostly $>5 \mathrm{~d}$ decade $^{-1}$ (Fig. 8c). Warm nights significantly increased in most regions, with the increasing trend generally $>5 \mathrm{~d} \mathrm{decade}^{-1}$, and the most significant increases can be seen in Northeast China, North China, Southwest China, and in South China coastal areas (Fig. 8d). 

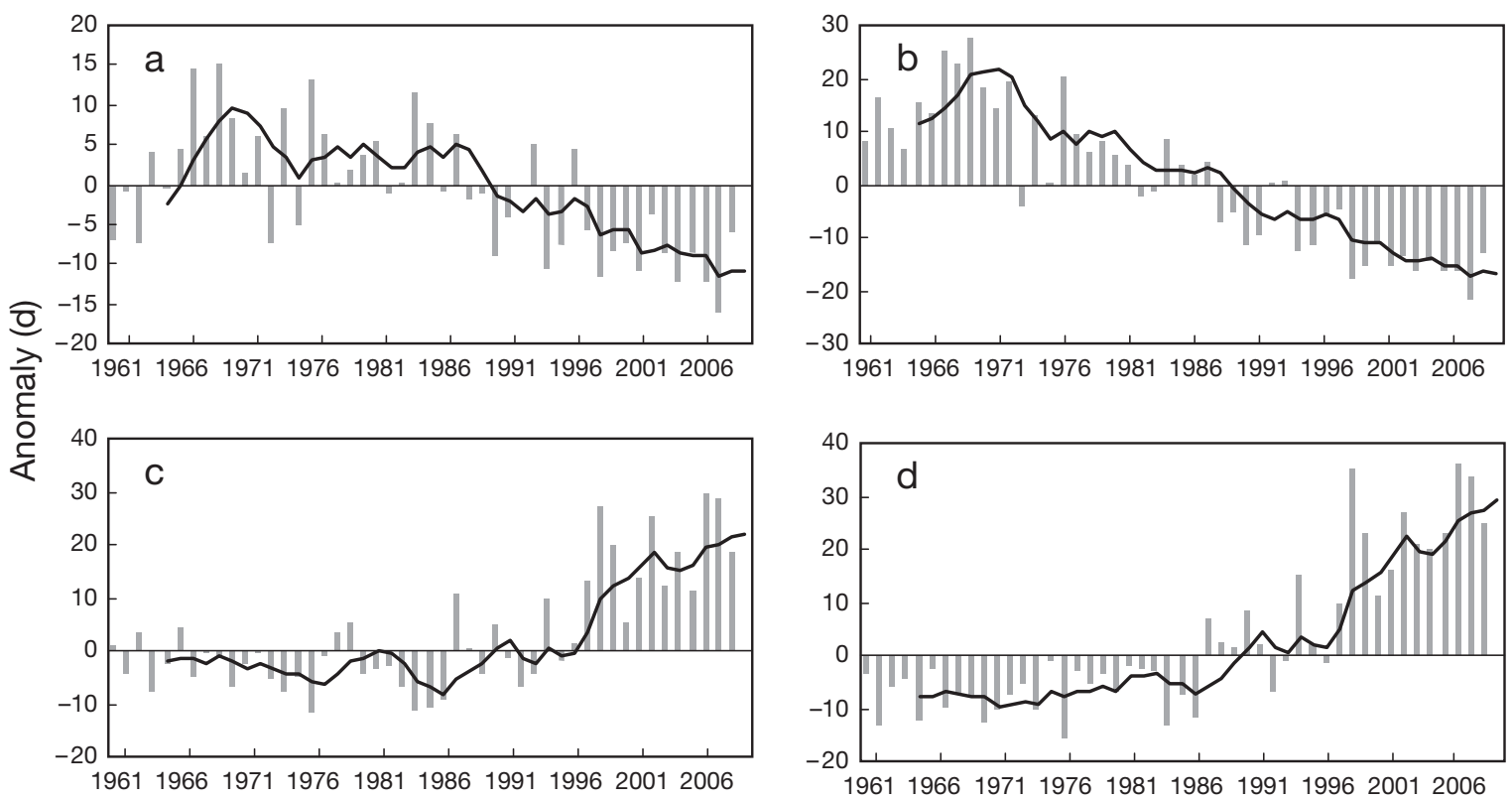

Fig. 7. Anomalies of the country-averaged (a) cool days (TX10p), (b) cool nights (TN10p), (c) warm days (TX90p), and (d) warm nights (TN90p) in mainland China, 1961-2008. The anomalies are relative to 1971-2000 mean values. The curves are 5 yr running means
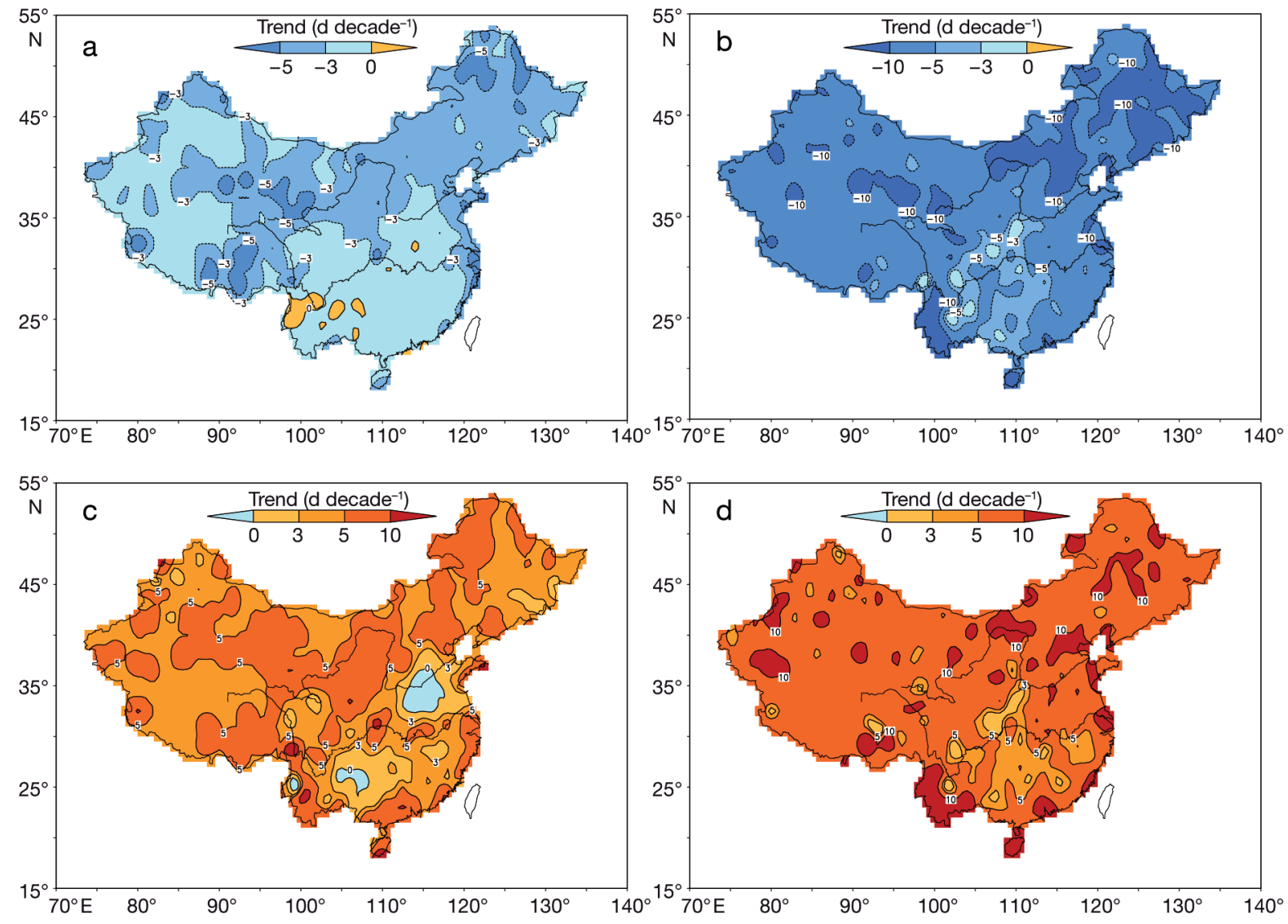

Fig. 8. Trends in distributions of (a) cool days (TX10p), (b) cool nights (TN10p), (c) warm days (TX90p), and (d) warm nights (TN90p) in mainland China, 1961-2008. Data given as d decade ${ }^{-1}$ 
Those areas with reduced cool days (nights) in the present study were approximately consistent with the research conclusions reached by Qian \& Lin (2004), in spite of the fact that the geographical extent in which cool days were significantly reduced was broader, while that showing an increasing trend shrunk. Similar situations could be seen for the areas with increased warm days (nights), except that the extent in which warm days were significantly increased was broader. The study period selected by Qian \& Lin (2004) was 1961-2000, and urban stations with populations $>500000$ were excluded from their analysis. These might be the main reasons for the differences mentioned above. The decreasing (increasing) trends of the relative cool (warm) indices have become stronger in the past decade, and the urbanization effect on mean and extreme temperatures of national stations, and particularly of big city stations, was significant (Ren et al. 2008, Zhou \& Ren 2009).

Therefore, the warm extreme indices have significantly increased, while the cold extreme indices have significantly decreased in the country during the past $48 \mathrm{yr}$. In addition, the indices related to minimum temperature have changed more significantly than those related to maximum temperature. The frequencies of cool days (nights) showed a rapid decline after the late 1980s, while the frequencies of warm days (nights) rose substantially in the mid-1990s. From a spatial distribution perspective, the relative indices changed more significantly in northern China.

In examining the seasonal change (Table 2), the reduction of cool days (nights) mainly occurred in winter, and the change was the weakest in summer. The most significant increase in frequencies of warm days (nights) occurred in autumn and summer.

Cool winter nights (days) and warm summer days (nights) are good indicators for cold periods and heat waves in climatic applications. Analysis of the 4 series of indices reveals that the most significant changes occurred for cool winter nights and warm summer nights, with respective trends reaching -10.9 and $9.3 \mathrm{~d}_{\text {decade }}$ - $^{-1}$ (Table 2, Fig. 9). The frequencies of cool winter nights (days) were relatively stable before the mid-1980s, but rapidly declined after 1986 and have generally remained at a low level in the last 2 decades (Fig. 9). The frequencies of warm summer (nights) days has continuously increased since the mid-1990s.

Fig. 10a shows that cool winter days significantly declined across the whole country, and the decreasing trends for nearly half of the stations were $>5 \mathrm{~d}_{\text {decade }}{ }^{-1}$. The areas with significant reduction were primarily in northern China, East China, and on
Table 2. Linear trends in seasonal cool nights and warm days in mainland China, 1961-2008. Data are given in d decade $^{-1} .{ }^{*}$ : statistically significant at the 0.05 confidence level

\begin{tabular}{|lcccc|}
\hline & $\begin{array}{c}\text { Cool } \\
\text { nights } \\
(\text { TN10p) }\end{array}$ & $\begin{array}{c}\text { Cool } \\
\text { days } \\
\text { (TX10p) }\end{array}$ & $\begin{array}{c}\text { Warm } \\
\text { nights } \\
\text { (TN90p) }\end{array}$ & $\begin{array}{c}\text { Warm } \\
\text { days } \\
\text { (TX90p) }\end{array}$ \\
\hline Spring & $-7.6^{*}$ & $-2.5^{*}$ & $8.1^{*}$ & $4.9^{*}$ \\
Summer & $-7.0^{*}$ & -1.4 & $9.3^{*}$ & $4.8^{*}$ \\
Autumn & $-7.9^{*}$ & $-4.3^{*}$ & $7.0^{*}$ & $5.7^{*}$ \\
Winter & $-10.9^{*}$ & $-5.4^{*}$ & $7.7^{*}$ & $5.3^{*}$ \\
\hline
\end{tabular}

the Qinghai-Tibet Plateau. Cool autumn days were reduced in most regions of China, but generally with decreasing trends of $<5 \mathrm{~d}_{\text {decade }}^{-1}$ (data not shown). The extents of areas with significantly decreasing trends were reduced in spring and summer. In summer, cool days even showed increasing trends at nearly half of the stations (data not shown). The areas with increasing trends were mainly in Central and East China. However, cool nights in 4 seasons were significantly reduced in most regions, especially in winter (Fig. 10b), and more than half of the stations showed decreasing trends of $>10 \mathrm{~d}$ decade $^{-1}$. The areas with significant reductions of cool nights were generally the same as those with reductions of cool days, but the intensity was stronger. During the other seasons, significant reductions in cool nights were also observed for most of the stations in northern China, while increasing trends occurred in some stations in southern China, but only during spring and summer. It is thus obvious that the frequencies of winter cold spells tended to decrease significantly in most regions of China, and a tremendous drop occurred in northern China, East China, and the Qinghai-Tibetan Plateau.

For warm autumn days, increasing trends were observed in most regions, notably in South China coastal areas, where significant upward trends occurred. Decreasing trends existed for warm winter and spring days in a few regions of Central and East China, while the areas with significant increases were mainly distributed on the Qinghai-Tibet Plateau and in the western part of Southwest China. Except for Central China and a part of South China in which a decreasing trend was observed for warm summer days (Fig. 10c), increasing trends were shown in most of the remaining regions, especially in North China, Northwest China, and in South China coastal areas. Warm nights for all seasons showed increasing trends across the whole country, and the significant increase not only occurred in North China and South- 

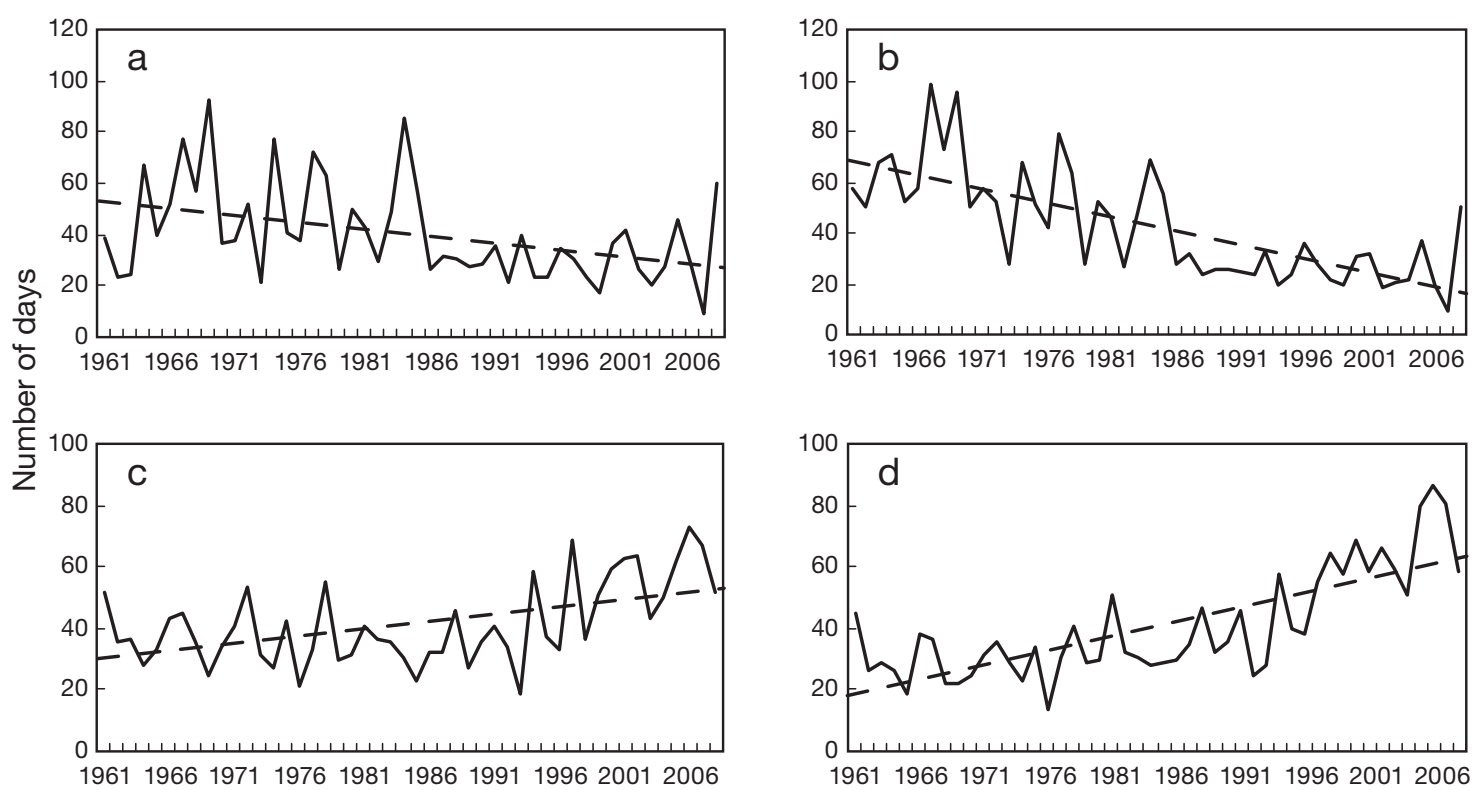

Fig. 9. Country-averaged (a) cool days (TX10p) and (b) cool nights (TN10p) for winter, and (c) warm days (TX90p) and (d) warm nights (TN90p) for summer in mainland China, 1961-2008. The dashed lines are linear trends
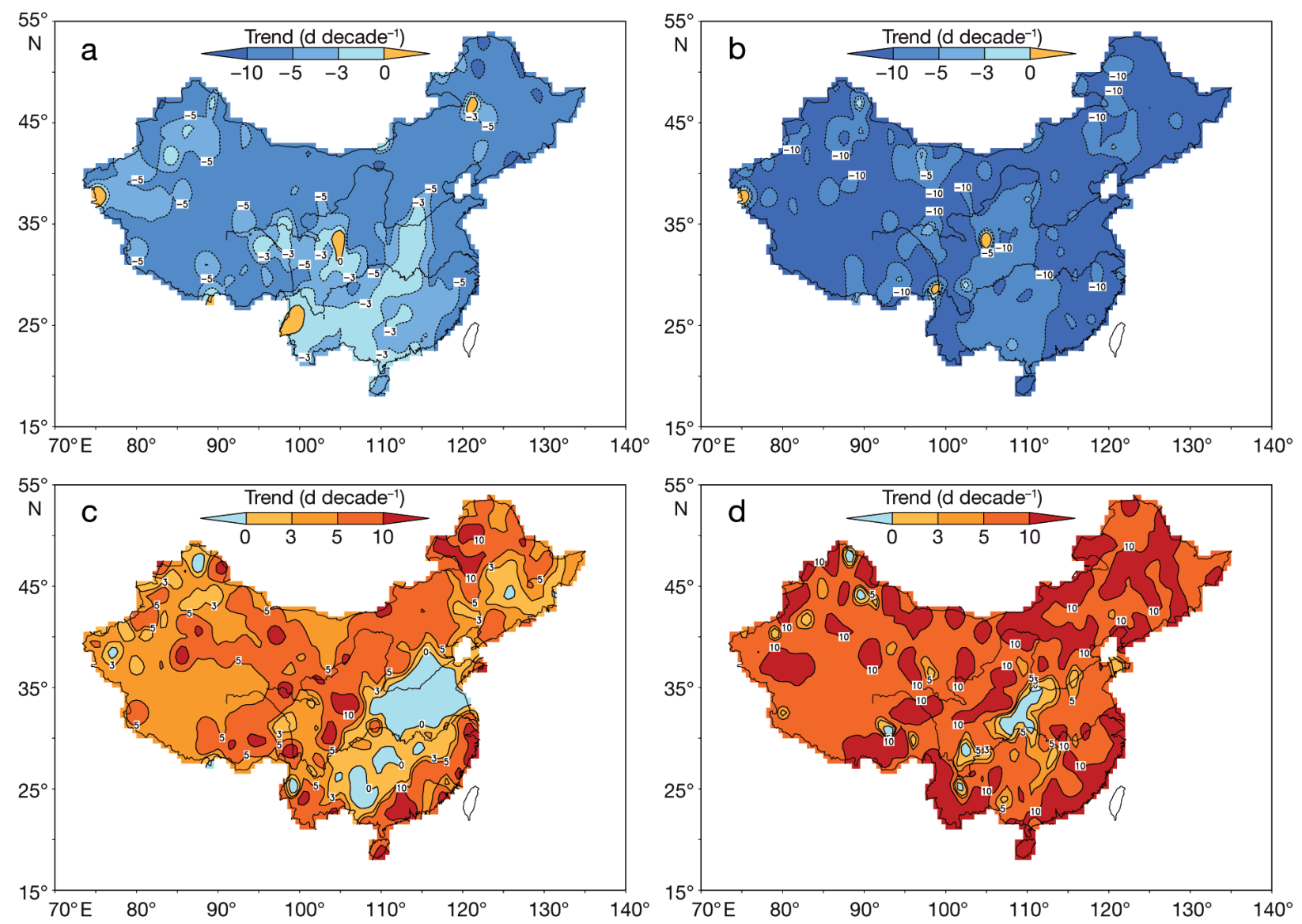

Fig. 10. Trends in (a) cool days (TX10p) and (b) cool nights (TN10p) for winter and (c) warm days (TX90p) and (d) warm nights (TN90p) for summer in mainland China, 1961-2008 
west China, but also in South China during summer and autumn. The stations at which warm summer nights were significantly increased were more extensively distributed (Fig. 10d), implying an increasing frequency of summer heat waves at some stations.

\section{DISCUSSION}

We have shown in the present study that, for mainland China on the whole, the indices of extreme warm temperatures have generally evidenced increasing trends, while indices of extreme cold temperatures have shown more significant decreasing trends. Overall these observations are consistent with the findings in previous publications (Yan et al. 2002, Zhai \& Pan 2003, Gong \& Han 2004, Qian \& Lin 2004, Tang et al. 2005), in spite of the fact that the country-averaged linear trends of the index series reported here are usually a bit stronger than those in the previous studies, mainly due to the different data processing methods used and time periods analyzed.

A major issue is the possible urbanization effect on the series of extreme temperature indices. According to analysis of the urbanization effect on mean maximum and minimum temperature trends in North China during the period 1961-2000 conducted by Zhou \& Ren (2009), an insignificant urbanization effect existed on the maximum temperature at national stations and at stations with populations of $<500000$. However, the region-averaged annual mean minimum temperature series for the national stations in North China was significantly affected by urbanization, with the contribution of urban warming to overall warming reaching $>50 \%$ (Zhou \& Ren 2009). The urbanization effect on the minimum temperature series of medium-sized and small city stations was somewhat weaker, but also statistically significant. Large urbanization effects on the extreme temperatures at the national stations in Shanghai and Beijing have also been reported by Cui et al. (2009) and Zhang et al. (2011). Significantly higher extreme maximum and minimum temperatures, and significantly more high-temperature days were found in the urban area of Shanghai than in its suburbs, while, since the 1980s, low temperature days in the urban area have been significantly reduced compared to those in the suburbs (Cui et al. 2009). In the case of Beijing station, frost days, cool nights, and DTR were significantly reduced between 1960 and 2008 due to the urbanization effect, while warm nights and mean minimum temperature increased significantly (Zhang et al. 2011). The above research results indicate that urbanization had impacts not only on daily and monthly mean temperatures at the national stations, but also particularly on the daily mean maximum and daily minimum temperatures and the resulting series of extreme temperature indices.

In order to better understand the magnitude of the urbanization effect on series of extreme temperature indices in a larger region, we chose North China as a case study to compare differences in a few extreme temperature indices between national stations and rural stations. Table 3 shows the extreme temperature indices of national and rural stations, as well as the urbanization effect and the contribution of the urbanization effect in North China during the period 1961-2008.

It is clear from Table 3 that the changes of the indices related to minimum temperatures were more significant for the national stations than for the rural stations. The urbanization effect on the index series was statistically significant at the 0.05 confidence level for the negative trends of frost days, DTR, cool nights, and cool days, and for the positive trends of summer days, tropical nights, $\mathrm{TNx}, \mathrm{TNn}$, and warm nights. For these indices, the contributions of the urbanization effect to the overall trends were also large, ranging from 10 to $100 \%$. The largest contributions come from tropical nights, DTR, $\mathrm{TNx}$, and $\mathrm{TNn}$, which all reached $>50 \%$, with DTR reaching $100 \%$. This means that the significant decrease in DTR observed for the national stations in North China was entirely caused by urbanization. This is an interesting finding because previous studies attributed most of the observed decrease in DTR to increasing cloud cover and atmospheric/soil moisture (Dai et al. 1999, Easterling et al. 2000, Duan \& Wu 2006) and to the possible influence of aerosols in industrial regions (Stone \& Weaver 2003, Zhou et al. 2009).

The urbanization effect exacerbated the trends of the cold and warm indices related to $T_{\min }$. However, the urbanization effects of the $T_{\max }$-related temperature indices were usually milder and generally did not pass the significance test at the 0.05 confidence level; this situation results from the fact that the urbanization effect on maximum temperature was much weaker and statistically less significant. An insignificant negative urbanization effect on the trends in maximum temperature and warm days might have resulted from the cooling effect of pollutants near the national stations as compared to rural stations. These results are basically consistent with our previous analysis of maximum and minimum temperature changes in North China using a different dataset of rural stations (Zhou \& Ren 2009). 
Table 3. Comparison of linear trends in series of extreme temperature indices between the national and rural stations in North China, 1961-2008. Data given as days or degrees Celsius per decade. ${ }^{*}$ : statistically significant at the 0.05 confidence level

\begin{tabular}{|lcccc|}
\hline & $\begin{array}{c}\text { National } \\
\text { station } \\
\left(X_{\mathrm{u}}\right)\end{array}$ & $\begin{array}{c}\text { Rural } \\
\text { station } \\
\left(X_{\mathrm{r}}\right)\end{array}$ & $\begin{array}{c}\text { Urbaniza- } \\
\text { tion effect } \\
\left(\Delta X_{\mathrm{ur}}\right)\end{array}$ & $\begin{array}{c}\text { Contribution } \\
(\%) \text { of urbaniza- } \\
\text { tion effect }\left(E_{\mathrm{u}}\right)\end{array}$ \\
\hline Absolute index & & & & \\
Frost days (FD0) & $-4.17^{*}$ & $-2.29^{*}$ & $-1.88^{*}$ & 45.1 \\
Summer days (SU25) & $2.52^{*}$ & $2.24^{*}$ & $0.28^{*}$ & 11.1 \\
Ice days (ID0) & $-2.32^{*}$ & $-2.56^{*}$ & 0.24 & -10.3 \\
Tropical nights (TR20) & $2.31^{*}$ & $0.83^{*}$ & $1.48^{*}$ & 64.1 \\
Extreme value index & & & & \\
Diurnal temperature range (DTR) & $-0.17^{*}$ & 0 & $-0.17^{*}$ & 100.0 \\
Maximum TX (TXx) & 0.04 & 0.06 & $-0.02^{*}$ & -50.0 \\
Maximum TN (TNx) & $0.26^{*}$ & $0.1^{*}$ & $0.16^{*}$ & 61.5 \\
Minimum TX (TXn) & $0.36^{*}$ & $0.34^{*}$ & 0.02 & 5.6 \\
Minimum TN (TNn) & $0.61^{*}$ & $0.3^{*}$ & $0.31^{*}$ & 50.8 \\
Relative index & & & & \\
Cool nights (TN10p) & $-8.61^{*}$ & $-4.85^{*}$ & $-3.76^{*}$ & 43.7 \\
Cool days (TX10p) & $-3.43^{*}$ & $-3.07^{*}$ & $-0.36^{*}$ & 10.5 \\
Warm nights (TN90p) & $8.07^{*}$ & $4.20^{*}$ & $3.87^{*}$ & 48.0 \\
Warm days (TX90p) & $3.83^{*}$ & $3.91^{*}$ & -0.08 & -2.0 \\
\hline
\end{tabular}

nificantly. The mean maximum temperature began to rise significantly after the 1990s, while the mean minimum temperature had begun to steadily rise as early as the late 1970 s. The reduction in DTR mainly occurred before the mid1980s, however, and the change thereafter became insignificant. TXn and TNn significantly increased after the mid1980s, while TXx and TNx did not increase until after the mid1990s. TXx and TNx in northern China rose significantly, but a downward trend was observed in the middle and lower reaches of the Yangtze River and in Southwest China. TXn and TNn significantly increased across the whole country.

(3) Although the warm indices increased significantly and cold indices decreased significantly, the series of the relative indices related to minimum temperature changed more significantly than those related to maximum temperature. The significant reduction of cool nights and days occurred after the late 1980 s, while the significant increase of warm nights and days occurred after the mid-1990s. The most significant changes in cool nights and days were in northern China, and the warm nights and days increased more substantially in Southwest China and in the coastal areas of South China.

(4) The significant reduction of cool days and nights mostly occurred in winter, and the frequencies of warm days and nights increased more significantly in autumn and summer. Warm summer days and nights increased more prominently in North China and in the coastal areas of South China. Thus, the winter cold spells tended to decline considerably in most regions of China, notably northern China, East China, and on the Qinghai-Tibet Plateau. The days with extreme high temperatures increased in most regions, mainly in summer, while the nights with extreme high temperatures increased more significantly, resulting in an increase of summer heat waves.

(5) The case study of North China proved that urbanization intensified the downward trend in cold index series and the upward trend in warm indices related to minimum temperature. The urbanization effect on the series of extreme temperature indices was statistically significant for the downward trends
(2) The mean and maximum (minimum) values of daily maximum and minimum temperatures showed overall increasing trends, and DTR decreased sig- 
in frost days, DTR, cool nights, and cool days, and for the upward trends in summer days, tropical nights, TNx, TNn, and warm nights. For these indices, the contributions of the urbanization effect to the overall trends ranged from 10 to $100 \%$, with the largest contributions coming from tropical nights, DTR, TNx, and TNn. The decrease in DTR at the national stations in North China was caused entirely by urbanization. However, the urbanization effect was rather weaker on the trends in the indices related to maximum temperatures. The case analysis shows that the urbanization effect on the trends in the series of extreme temperature indices should not be ignored for mainland China, and more attention needs to be given to the issue in future studies.

Acknowledgements. The present study was financially supported by the Ministry of Science and Technology of China (2007BAC29B02 and 2007BAC03A01).

\section{LITERATURE CITED}

Alexander LV, Zhang X, Peterson TC, Caesar J and others (2006) Global observed changes in daily climate extremes of temperature and precipitation. J Geophys Res 111:D05109. doi:10.1029/2005JD006290

> Brabson BB, Palutikof JP (2002) The evolution of extreme temperatures in the central England temperature record. Geophys Res Lett 29:2163-2166

Choi G, Collins D, Ren GY, Trewin B and others (2009) Changes in means and extreme events of temperature and precipitation in the Asia-Pacific Network region, 1955-2007. Int J Climatol 29:1906-1925

Cui LL, Shi J, Zhou WD (2009) Characteristics of extreme temperature variations and their response to urbanization in Shanghai. Sci Geogr Sin 29:93-97 (in Chinese)

$>$ Dai A, Trenberth KE, Karl TR (1999) Effects of clouds, soil moisture, precipitation and water vapor on diurnal temperature range. J Clim 12:2451-2473

> Ding T, Qian WH, Yan ZW (2009) Changes in hot days and heat waves in China during 1961-2007. Int J Climatol 30:1452-1462

Ding YH, Ren GY, Shi GY, Gong P and others (2006) National assessment report of climate change. I. Climate change in China and its future trend. Adv Clim Change Res 2:3-8 (in Chinese)

Duan AM, Wu GX (2006) Change of cloud amount and the climate warming on the Tibetan Plateau. Geophys Res Lett 33:L22704. doi:10.1029/2006GL027946

Easterling DR, Evans JL, Groisman PY, Karl TR, Kunkel KE, Ambenje P (2000) Observed variability and trends in extreme climate events: a brief review. Bull Am Meteorol Soc 81:417-425

Gong DY, Han H (2004) Extreme climate events in northern China over the last 50 years. Acta Geophys Sin 59: 230-238 (in Chinese)

$\mathrm{Hu}$ YC, Dong WJ, He Y (2007) Progress of the study of extreme weather and climate events at the beginning of the twenty-first century. Adv Earth Sci 22:1066-1075 (in Chinese)
IPCC (Intergovernmental Panel on Climate Change) (2007) Climate change 2007: the physical science basis. Cambridge University Press, Cambridge

> Jones PD, Hulme M (1996) Calculating regional climatic time series for temperature and precipitation: methods and illustrations. Int J Climatol 16:361-377

Kendall MG, Gibbons JD (1981) Rank correlation methods, 5th edn. Edward Arnold, London

> Klein Tank AMG, Konnen GP (2003) Trends in indices of daily temperature and precipitation extremes in Europe, 1946-99. J Clim 16:3665-3680

> Li QX, Liu XN, Zhang HZ, Peterson TC, Easterling DR (2004) Detecting and adjusting temporal inhomogeneity in Chinese mean surface air temperature data. Adv Atmos Sci 21:260-268

Liu XH, Ji ZJ, Wu HB, Yu XJ (2006) Characteristics and interdecadal difference of daily temperature and precipitation extremes in China for the last 40 years. J Trop Meteorol 22:618-624 (in Chinese)

Liu XN, Li QX (2003) Research of the inhomogeneity test of climatological data series in China. Acta Meteorol Sin 17:492-502

Manton MJ, Della-Marta PM, Haylock MR, Hennessy KJ and others (2001) Trends in extreme daily rainfall and temperature in southeast Asia and the south Pacific: 1961-1998. Int J Climatol 21:269-284

> Qian WH, Lin X (2004) Regional trends in recent temperature indices in China. Clim Res 27:119-134

Ren GY, Chu ZY, Zhou YQ, Xu MZ and others (2005) Recent progress in studies of regional temperature changes in China. Clim Environ Res 10:701-716 (in Chinese)

Ren GY, Zhou YQ, Chu ZY, Zhang AY, Guo J, Liu XF (2008) Urbanization effects on observed surface air temperature trends in North China. J Clim 21:1333-1348

Ren GY, Feng GL, Yan ZW (2010a) Progresses in observation studies of climate extremes and changes in mainland China. Clim Environ Res 15:337-353 (in Chinese)

Ren GY, Zhang AY, Chu ZY, Zhou JX, Ren YY, Zhou YQ (2010b) Principles and procedures for selecting reference surface air temperature stations in China. Meteorol Sci Technol 38:78-85 (in Chinese)

Ren YY, Ren GY (2011) A remote-sensing method of selecting reference stations for evaluating urbanization effect on surface air temperature trends. J Clim 24:3179-3189

Shi J, Ding YH, Cui LL (2009) Climatic characteristics of extreme maximum temperature in East China and its causes. Chin J Atmos Sci 33:347-358 (in Chinese)

Stone DA, Weaver AJ (2003) Factors contributing to diurnal temperature range trends in twentieth and twenty-first century simulations of the CCCma coupled model. Clim Dyn 20:435-445

Tang HY, Zhai PM, Wang ZY (2005) On change in mean maximum temperature, minimum temperature and diurnal range in China during 1951-2002. Clim Environ Res 10:728-735 (in Chinese)

Vincent LA, Peterson TC, Barros VR, Marino MB and others (2005) Observed trends in indices of daily temperature extremes in South America 1960-2000. J Clim 18: 5011-5023

Yan Z, Jones PD, Davies TD, Moberg A and others (2002) Trends of extreme temperatures in Europe and China based on daily observations. Clim Chang 53:355-392

Yang P, Liu WD, Wang QG, Xiong KG, Hou W (2010) The climate change trend and seasonal characteristics of daily temperature extremes in China for the last 40 years. J Appl Meteorol Sci 21:29-36 (in Chinese) 
Ye DX, Zou XK, Zhang Q, Chen XY (2008) An analysis of climatic characteristics of high temperature in the three gorges area. J Trop Meteorol 24:200-204 (in Chinese)

You QL, Kang SC, Li CL, Yan YP, Yan SY (2008) Change in extreme temperature over Sanjiangyuan region in the period from 1961 to 2005. Resour Environ Yangtze Basin 17:233-236 (in Chinese)

Zhai PM, Pan XH (2003) Trends in temperature extremes during 1951-1999 in China. Geophys Res Lett 30: 1913-1916

Zhang AY, Ren GY, Zhou JX, Chu ZY, Ren YY, Tang GL (2010) On the urbanization effect on surface air temperature trends over China. Acta Meteorol Sin 68:957-966 (in Chinese)

Zhang DQ, Qian ZH (2008) Analysis of extreme events in China's temperature in the recent 50 years using a detection method based on medians. Acta Phys Sin 57:

Submitted: February 25, 2011; Accepted: September 13, 2011
4634-4640 (in Chinese)

Zhang L, Ren GY, Liu J, Zhou YQ, Ren YY, Zhang AY, Feng YW (2011) Urban effect on trends of extreme temperature indices at Beijing Station. Chin J Geophys 54: 1150-1159 (in Chinese)

Zhang X, Yang F (2004) RClimDex (1.0) user manual. Climate Research Branch, Environment Canada, Downsview, Ontario

Zhou LM, Dickinson RE, Dai AG, Dirmeyer P (2009) Detection and attribution of anthropogenic forcing to diurnal temperature range changes from 1950 to 1999: comparing multi-model simulations with observations. Clim Dyn 35:1289-1307

Zhou YQ, Ren GY (2009) The effect of urbanization on maximum and minimum temperatures and daily temperature range in North China. Plateau Meteorol 28:1158-1166 (in Chinese)

Proofs received from author(s): November 14, 2011 